\title{
CULTURA, POLÍTICA E DESENVOLVIMENTO NO PENSAMENTO DE CELSO FURTADO
}

\author{
Fabio Akira Shishito ${ }^{1}$
}

RESUMO: Celso Furtado está no rol dos principais pensadores sociais da América Latina. Octavio Rodriguez afirma que há algo de distintivo na obra de Furtado: trata-se de uma conexão declarada entre cultura e desenvolvimento, algo que aparece com mais clareza em uma fase adiantada de sua produção. Mas, o papel que cumpre a cultura e o que exatamente Furtado tinha em mente quando se referia a esta dimensão da vida social não são elementos sistematizados na obra do autor. O desenvolvimento nunca foi, para Furtado, um problema exclusivamente econômico, aliás, é contra essa visão que ele realizou todo seu empreendimento intelectual. No pano de fundo de sua teoria do (sub)desenvolvimento está um debate de natureza epistemológica acerca dos modos de apreensão do fenômeno econômico. Em "O mito do desenvolvimento econômico" ele assevera que toda escolha no campo da economia é resultada de reflexões com projeções no tempo, isto é, num projeto político. Em recente ensaio publicado postumamente ele perseguiu tal problema se perguntando: "Que somos?". O que somos como coletividade e o que projetamos como horizonte de possibilidades são aspectos centrais para pensarmos teoricamente o desenvolvimento e o subdesenvolvimento. Objetivando explorar os caminhos analíticos e políticos deste problema, a questão central deste artigo é o seguinte: Qual o lugar e o papel da cultura na noção furtadiana de desenvolvimento?

Palavras-chave: Desenvolvimento. Subdesenvolvimento. Cultura. Celso Furtado.

\section{CULTURE, POLITICS AND DEVELOPMENT IN THE THOUGHT OF CELSO FURTADO}

ABSTRACT: Celso Furtado is among the leading social thinkers in Latin America. Octavio Rodriguez states that there is something distinctive about Furtado's work: it is a declared connection between culture and development, something that appears more clearly in an advanced stage of his production. But the role that culture fulfills and what Furtado precisely had in mind when referring to this dimension of social life are not systematized elements in

\footnotetext{
${ }^{1}$ Graduação em Ciências Sociais (UEL), Mestrado em Ciências Sociais (UEL) e Doutorado (em andamento) em Sociologia (USP). Endereço Eletrônico: akira.shishito@ hotmail.com.
} 
the author's work. Development was never, for Furtado, an exclusively economic problem; in fact, it is against this view that he carried out his entire intellectual enterprise. In the background of his theory of (under) development is a debate of the epistemological nature about the modes of apprehension of the economic phenomenon. In "The Myth of Economic Development" he asserts that every choice in the field of economics is the result of reflections with projections in time, that is, in a political project. In a recent posthumous essay he pursued such a problem by asking himself: "What are we?" What we are as a collectivity and what we project as a horizon of possibilities are central to thinking theoretically about development and underdevelopment. In order to explore the analytical and political paths of this problem, the central question of this article is: What is the place and role of culture in the Furtadian notion of development?

Keywords: Development. Underdevelopment. Culture. Celso Furtado.

\section{CULTURA, POLÍTICA Y DESARROLLO EN EL PENSAMIENTO DE CELSO FURTADO}

RESUMEN: Celso Furtado está en el rol de los principales pensadores sociales de América Latina. Octavio Rodríguez afirma que hay algo de distintivo en la obra de Furtado: se trata de una conexión declarada entre cultura y desarrollo, algo que aparece con más claridad en una fase avanzada de su producción. Pero el papel que cumple la cultura y lo que exactamente Furtado tenía en mente cuando se refería a esta dimensión de la vida social no son elementos sistematizados en la obra del autor. El desarrollo nunca fue, para Furtado, un problema exclusivamente económico, por cierto, es contra esa visión que él realizó todo su emprendimiento intelectual. En el fondo de su teoría del (sub) desarrollo está un debate de naturaleza epistemológica acerca de los modos de aprehensión del fenómeno económico. En "El mito del desarrollo económico" él asevera que toda elección en el campo de la economía es resultado de reflexiones con proyecciones en el tiempo, es decir, en un proyecto político. En un reciente ensayo publicado postumamente él persiguió tal problema preguntándose: "¿Qué somos?". Lo que somos como colectividad y lo que proyectamos como horizonte de posibilidades son aspectos centrales para pensar teóricamente el desarrollo y el subdesarrollo. Con el objetivo de explorar los caminos analíticos y políticos de este problema, la cuestión central de este artículo es: ¿Cuál es el lugar y el papel de la cultura en la noción furtadiana de desarrollo?

Palavras Clave: Desarrollo. Subdesarrollo. Cultura. Celso Furtado.

\section{Introdução}

Celso Furtado está, seguramente, entre os principais pensadores da América Latina. Seus escritos possuem valiosas contribuições em várias áreas das ciências sociais, mas, é sobretudo seu empreendimento no campo dos estudos do desenvolvimento que lhe aufere distinção. Octavio Rodriguez afirma que há algo de destaque na obra de Celso Furtado mesmo se a analisarmos no conjunto do chamado pensamento estruturalista latino americano. "Tratase da questão da cultura ou, com mais propriedade, do estabelecimento de uma ligação explícita entre cultura e desenvolvimento" (RODRIGUEZ, 2007, p. 5). Mas, o papel que 
cumpre a cultura no processo de desenvolvimento e o que exatamente Furtado tinha em mente quando se referia a esta dimensão da vida social não são elementos sistematizados na obra do autor.

O desenvolvimento nunca foi, para Furtado, um problema exclusivamente econômico; aliás, é contra essa visão que ele realizou todo seu empreendimento intelectual. No pano de fundo de sua teoria do (sub) desenvolvimento está um debate de natureza epistemológica acerca dos modos de apreensão do fenômeno econômico. Em "O mito do desenvolvimento econômico" ele assevera: "toda decisão econômica é parte de um conjunto de decisões com importantes projeções no tempo. Essas decisões encontram sua coerência última num projeto que introduz um sentido unificador na ação do agente" (FURTADO, 1974, p. 112, grifo no original). Tal concepção reforça um argumento já anunciado na década de 1960: Não "acreditamos [diz Furtado] em ciência econômica pura, isto é, independente de um conjunto de princípios de convivência social preestabelecidos, de julgamentos de valor" (1962, p. 81).

O que o autor defende, efetivamente, é que, se bem o processo de desenvolvimento contenha uma dimensão econômica, as direções, as características e as escolhas que permeiam a dinâmica econômica formam, necessariamente, um problema político. Portanto, um problema cuja raiz consiste no modo como se organiza o poder. Além do mais, as formas de distribuição do poder parecem estar vinculadas, nos escritos de Furtado, pelos menos com mais clareza em seus escritos tardios, a um problema de ordem cultural. Assim, a questão central deste artigo se define da seguinte maneira: Qual o lugar e o papel da cultura na dinâmica de distribuição/concentração de poder no pensamento furtadiano?

Não há grandes dissonâncias, entre os interpretes, relativas ao período em que Celso Furtado inicia suas reflexões sobre a dimensão cultural do desenvolvimento (CEPÊDA, 2014; BRANDÃO, 2012; KORNIS, 2013; ESTEVES, 2014). Com efeito, Criatividade $e$ dependência na civilização industrial (FURTADO, 1978; 2008) parece ser a obra que sintetiza inicialmente suas reflexões sobre a temática, embora, para os objetivos deste artigo, o texto de 1974 O mito do desenvolvimento econômico tenha igual relevância. Isso porque é neste livro que se delineia com clareza o argumento de que o desenvolvimento não é senão um problema radicalmente político.

$\mathrm{O}$ artigo se divide, assim, em três partes, além desta breve introdução. Na primeira delas explorar-se-á o caráter ambíguo da noção de desenvolvimento. Posteriormente, discutirse-á o lugar da dimensão cultural no conceito de desenvolvimento de Celso Furtado e, 
finalmente, uma terceira e "conclusiva" seção foi dedicada ao modo como se entrelaçam, desde uma perspectiva praxiológica, os conceitos de cultura, poder e desenvolvimento.

\section{Ambiguidades do desenvolvimento}

"Desenvolvimento" foi, possivelmente, uma das mais disputadas noções do ambiente intelectual (acadêmico e não acadêmico) da segunda metade do século XX. Pensadores como Walt Rostow, Gunnar Myrdal, Raul Prebisch, Celso Furtado, Amartya Sen, Albert Hirschman, Arthur Lewis, entre muitos outros, participaram de um frutífero debate ao longo de décadas ao redor do conceito de desenvolvimento e de seu par (hoje em relativo desuso) subdesenvolvimento ${ }^{2}$.

Ao longo das últimas seis décadas e, em alguma medida, resultante do conflito acima citado, o conceito foi recebendo variadas adjetivações (econômico, social, sustentável, humano, equitativo, includente etc.), sinal de que subsiste uma disputa pela definição de que seriam, afinal, os conteúdos do desenvolvimento. Do ponto de vista da periferia do sistema capitalista, e mais particularmente do Brasil, Celso Furtado foi um dos pensadores que mais contribuiu para este debate e a extensa obra que produziu segue sendo objeto de pesquisa nas diversas áreas das ciências humanas. Sua noção de desenvolvimento, no entanto, foi sendo elaborada e reelaborada ao longo de seus mais de cinquenta anos dedicados à temática. É relativamente conhecida sua abordagem de inspiração estruturalista (BIELSCHOWSKY, 2009) de cujo diagnóstico da deterioração dos termos de intercâmbio ${ }^{3}$ (e demais assimetrias da configuração centro-periferia) derivaram as propostas de substituições de importações, estas tidas como referência das políticas de desenvolvimento econômico no Brasil, nas primeiras décadas do após-Guerra.

Os desdobramentos deste período ${ }^{4}$ e, principalmente, o após-Golpe civil-militar de 1964 parecem desvelar, aos poucos, o alto preço social que estava sendo pago pelas políticas desenvolvimentistas orientadas pela industrialização substitutiva. Abria-se um paradoxo intelectual embaraçoso: repensar as condições para superação do subdesenvolvimento, reconhecer os limites da noção de desenvolvimento e, ao mesmo tempo, compreender as

\footnotetext{
${ }^{2}$ Um mapeamento desse debate pode ser visto, entre outros, em: AGARWALA e SINGH (2010); MEIER e SEERS (1986); HIRSCHMAN (1982).

${ }^{3}$ A teoria da deterioração dos termos de intercambio foi formulada no interior da Cepal, mas suas linhas centrais são atribuídas, principalmente, a Raul Prebisch.

4 Celso Furtado teve participação ativa na formulação de políticas econômicas de desenvolvimento em momentos relevantes como a missão Cepal-BNDE, que deu origem ao Banco e como ministro do planejamento na gestão João Goulart, momento em que coordenou a elaboração do chamado Plano Trienal.
} 
dificuldades em abandoná-la. Com efeito, não se abandonou a noção de desenvolvimento, mas, as disputas pela definição de seu conteúdo percorrem caminhos variados. Para Celso Furtado qualquer tentativa de elaboração conceitual do desenvolvimento passava pelo entendimento da natureza do subdesenvolvimento e isso, diz ele, "não é tarefa fácil: muitas são as suas dimensões e as que são facilmente visíveis nem sempre são as mais significativas" (FURTADO, 1974, p. 22).

São as reflexões produzidas a partir dessa compreensão que se observa a inserção da cultura como variável definidora. O desenvolvimento, então, passa a ser entendido como um processo socioeconômico que tem origem no modo com as diferentes sociedades exercem suas capacidades criativas face àquilo que produzem como excedentes. A ideia de excedentes, vale dizer, extrapola as ideias de lucro ou mais-valia e refere-se, também, aos muitos elementos que conferem poder em níveis desiguais aos diferentes grupos sociais. Desse modo, os rendimentos econômicos podem ser vistos como excedentes, mas também as condições educacionais, habitacionais e de saúde, por exemplo, conformam "produtos" a respeito dos quais as sociedades elaboram formas próprias de distribuição (FURTADO, 2008).

A ideia de desenvolvimento em Furtado é potencialmente reveladora, desse modo, das características imprimidas historicamente ao processo político em sociedades desiguais. Isso porque, diz ele, “esse movimento não é errático: o essencial da atividade criadora evolui no âmbito de um espaço estruturado [...]. A sociedade primeiramente reproduz-se, e ao fazê-lo imprime uma coerência diacrônica à cultura" (FURTADO, 2008, p. 113). Aqui observamos uma dica fundamental do pensamento furtadiano, qual seja, a ideia de que as formas de manifestação cultural são produzidas e reproduzidas em condições estruturais específicas. Apesar da aparência de obviedade tal enunciado abre caminho para uma reflexão sociológica de grande alcance: as formas como produzimos simbolicamente o mundo guardam relações de proximidade com as formas como produzimos materialmente o mundo.

Para exemplificar, um dos principais processos inventivos que marcam, política e economicamente, a fundação do que conhecemos por modernidade, as revoluções burguesas, produz um refinamento de dois poderosos dispositivos culturais, o racionalismo e o empirismo. Criadores e criaturas da modernidade, esses dois dispositivos marcarão profundamente nossas formas de ver, produzir, avaliar e projetar o mundo social. Se na Idade Média a visão de mundo orientava-se por um retorno glorioso ao passado, na modernidade "racionalizada" "tudo podia ser posto em dúvida, e a coesão social passava a depender mais da visão do futuro do que da memória do passado" (FURTADO, 2008, p. 99). 
A visão do futuro sobre a qual se alicerçara o processo de mudança será a noção de progresso. Sobretudo a partir do século XIX predominará uma concepção do desenrolar histórico como um processo dotado de uma diretividade progressiva. A ideia de progresso, mais do que base para elaboração de projetos políticos, formará, efetivamente, uma espécie de substrato cultural do mundo moderno ocidental, isto é, formará uma das noções essenciais da epistemologia moderno-ocidental. Os primeiros abalos deste alicerce serão sentidos, apenas, no século XX, principalmente após os adventos das Grandes Guerras. A noção de progresso será, aos poucos, substituída pela concepção de desenvolvimento. Mas os fundamentos epistemológicos não desaparecerão, assim, facilmente. Norbert Elias foi um dos que percebeu e problematizou as implicações desse processo.

\begin{abstract}
O conceito de desenvolvimento social traz, atualmente, um estigma derivado da imagem desse desenvolvimento que predominou nos séculos XVIII e XIX. Quem quer que retome esse conceito no final do século XX e antecipando o século XXI, ou seja, numa curva mais elevada da espiral, corre o risco de granjear o desprezo da geração que cresceu durante o grande e traumático colapso do antigo conceito de desenvolvimento - o conceito que prometia o progresso constante da humanidade, elevando-se em linha reta para um estado mais feliz. Contaminados pelo estigma da desilusão, conceitos como 'progresso' e 'desenvolvimento' pareceram tornar-se impossíveis de usar na pesquisa (ELIAS, 1994, p. 144-145).
\end{abstract}

Os apontamentos de Elias corroboram a ideia furtadiana de que uma dimensão ideológica do desenvolvimento cumpriu papel de relevo na história do Ocidente. Aqui cabe destacar que o desenvolvimento não é entendido por Furtado exclusivamente como ilusão, ou seja, sua dimensão ideológica é parte de uma engrenagem complexa cujo andamento reflete diretamente no tecido e nas formas de convivência social. Diz ele:

Independente de outras considerações que sobre este ponto se possam fazer, cabe assinalar que a crescente subordinação do processo social aos critérios de racionalidade instrumental teria que acarretar modificações em profundidade na organização social (FURTADO, 1980, p. 5).

Veja-se que o autor está propondo uma compreensão do desenvolvimento como processo de mudança social no qual uma dimensão cultural (a forma predominante de simbolizar o mundo) exerce influência tanto sobre as possibilidades criativas de elaboração de projetos políticos, como sobre as formas concretas de realizá-los. O que está no pano de fundo da proposição é a distinção teórica entre desenvolvimento e modernização. Modernização é entendida como expressão da racionalização, do incremento da técnica e da racionalidade 
instrumental $^{5}$. O desenvolvimento, por seu turno, é o processo político de exercício da criatividade em face do produto socialmente construído. Esse tipo de proposição teórica, a de pensar o desenvolvimento como aspecto da mudança social mais ampla tem lastro no pensamento social brasileiro e encontra sistematizações em autores como Luis de Aguiar Costa Pinto (1965), Antonio Luis Machado Neto (1963), Luiz Pereira (1970).

Celso Furtado figura, sem dúvida, entre os principais pensadores dessa linhagem. Para ele, o que assistimos historicamente, no Brasil, foi um processo político reiterado de modernizações em favor do estilo de vida "dos estamentos sociais de rendas médias e altas, desatendendo-se a satisfação das necessidades mais elementares da massa da população" (FURTADO, 1984 in FURTADO, 2012, p. 30). Ocorre que esse processo orientou-se, em significativa medida, pela noção de desenvolvimento, daí a ideia de que trata-se de uma ideiaforça repleta de ambiguidades. Em importante texto de 1980 Furtado explica os eixos dessa ambiguidade.

O conceito de desenvolvimento tem sido utilizado, com referência à história contemporânea, em dois sentidos distintos. O primeiro diz respeito à evolução de um sistema social de produção na medida em que este, mediante a acumulação e progresso das técnicas, torna-se mais eficaz, ou seja, eleva a produtividade do conjunto de sua força de trabalho (FURTADO, 1980, p. 15).

E segue: "O segundo sentido em que se faz referência ao conceito de desenvolvimento relaciona-se com o grau de satisfação das necessidades humanas. A ambiguidade neste caso aumenta" (FURTADO, 1980, p. 16). Isso porque é tarefa difícil mensurar os graus de satisfação dos anseios dos homens e das mulheres. Num nível mais elementar, pode-se, é verdade, observar essa satisfação com relativa objetividade; é o caso das condições de alimentação, de vestimenta ou habitação. Entretanto, explica Furtado, quanto mais nos afastamos desse plano elementar mais necessário se torna a mobilização de um sistema de valores "pois a ideia mesma de necessidade humana, quando não referida ao essencial, tende a perder nitidez fora de determinado contexto cultural" (1980, p. 16).

No primeiro sentido ele assume uma feição descritiva, no segundo destaque-se o elemento normativo. Essa ambiguidade, segundo entendemos, cumpre um papel importante para o que chamaremos de uma dimensão ideológica do desenvolvimento. "A utilização do mesmo conceito - o de desenvolvimento -, com referência aos dois processos históricos, envolve ambiguidades que somente um espesso véu ideológico consegue ocultar"

\footnotetext{
5 Furtado tratará com profundidade da temática da modernização e seus impactos sobre o processo de desenvolvimento em "Criatividade e dependência", texto de 1978.
} 
(FURTADO, 2008, p.98). Para o autor de $O$ mito do desenvolvimento econômico, assim como para grande parte dos economistas (e demais pensadores sociais) estruturalistas latinoamericanos, era evidente que “[...] a hipótese de generalização, no conjunto do sistema capitalista, das formas de consumo que prevalecem atualmente nos países cêntricos, não têm cabimento dentro das possibilidades evolutivas aparentes desse sistema" (FURTADO, 1974, p. 75).

A despeito da impossibilidade objetiva - uma vez que mundo físico não suportaria de alargamento do estilo de vida das minorias privilegiadas à toda humanidade, a noção de desenvolvimento segue na base dos procedimentos de política econômica dos países subdesenvolvidos. Afinal:

\begin{abstract}
como negar que essa ideia tem sido de grande utilidade para mobilizar os povos da periferia e leva-los a aceitar enormes sacrifícios, para legitimar a destruição de formas de cultura arcaicas, para explicar e fazer compreender a necessidade de destruir o meio físico, para justificar formas de dependência que reforçam o caráter predatório do sistema produtivo? (FURTADO, 1974, p. 75).
\end{abstract}

Ora, o desenvolvimento como ideia-força, essa dimensão ideológica do conceito só pode exercer com êxito sua função no quadro de uma formatação cultural específica. Talvez venha daí o entendimento de Veiga (2010) de que faltam as contribuições de uma antropologia do desenvolvimento para equacionar a ideia de desenvolvimento em sua expressão mítica. Ou, ainda, as sugestões de Guy Hermet (2002), acerca da necessidade de uma espécie de topografia cultural para tornar as políticas de desenvolvimento sensíveis às comunidades que são objeto dos projetos. De toda maneira, graças a referida dimensão, diz Furtado:

tem sido possível desviar as atenções da tarefa básica de identificação das necessidades fundamentais da coletividade e das possibilidades que abre ao homem o avanço da ciência, para concentrá-las em objetivos abstratos como são os investimentos, as exportações e o crescimento (1974, p. 75-76).

Há uma Antropologia do Desenvolvimento, cumpre dizer, que tem se debruçado sobre a temática. No entanto, seus esforços concentram-se, majoritariamente, em propor o obituário do conceito como ideia-força para guiar os esforços políticos, sobretudo, dos países periféricos ${ }^{6}$.

\title{
3. Poder e cultura: dimensões mitificadas do subdesenvolvimento
}

${ }^{6}$ Cf. Wolfgang Sachs (1996). 
A elaboração da teoria do subdesenvolvimento de Celso Furtado tem um claro e importante ponto de referência: um embate direto com concepções do desenvolvimento e do subdesenvolvimento entendidos como etapas necessárias do processo histórico. $\mathrm{O}$ combate a esse tipo de interpretação faseológica está na base de sua concepção de desenvolvimento e de subdesenvolvimento. No pensamento furtadiano, portanto, o subdesenvolvimento não diz respeito a uma fase histórica, antes, é uma forma particular de organização socioeconômica típica de determinadas regiões do planeta, principalmente aquelas consideradas pertencentes à periferia do sistema capitalista e resultadas do modo de inserção na divisão internacional do trabalho.

Dizer que o subdesenvolvimento é uma forma e não uma fase é, sobretudo, afirmar que se trata de um processo histórico com particularidades que não devem ser descartadas no processo analítico. Isso implica em assumir que suas configurações sociais são específicas e que, portanto, seus problemas e suas possibilidades devem ser analisados historicamente. Mais, é preciso compreender as características da história econômica, a natureza de suas relações comerciais com o exterior, o padrão de organização social, como se estabeleceram as relações de poder em seu interior, de que forma a sociedade lida com a política, como a sociedade manifesta sua criatividade.

Superar o subdesenvolvimento, nesse sentido, é uma tarefa, antes de tudo, social e política. Isso significa, entre outras coisas, que o processo sociocultural, isto é, a história da construção dos valores e significados que orientam a prática social forma um importante pilar do subdesenvolvimento e, consequentemente, de sua possibilidade de superação. A invenção de novas formas de se organizar socialmente é, nas palavras de Furtado, "a expressão da capacidade criadora do homem em uma de suas formas mais nobres" (2002, p. 62).

Os esforços de Furtado direcionam-se, assim, para a inserção da dimensão cultural no processo explicativo do subdesenvolvimento. Desse modo, se é correta a tese da dependência econômica advinda das formas subordinadas de participação na divisão internacional do trabalho, também parece contar, como aspecto do problema, os desdobramentos culturais desse processo. A forma como pensamos, agimos e damos significados às coisas não é independente de nossas relações econômicas. Essa percepção aparece de forma relativamente tardia no pensamento de Furtado, mas, talvez tenha sido a partir dela que sua teoria do subdesenvolvimento tenha ganhado maior amplitude (e, por outro lado, talvez o deixado mais pessimista). Interessa-nos, pois, a seguinte questão: Como Celso Furtado interpreta o processo cultural brasileiro? 
Para o autor é preciso observá-lo desde o processo de expansão da cultura europeia e este, segundo ele, tem dois caminhos distintos. O primeiro tem como ponto de partida a nova leitura da cultura clássica que chamamos de Renascimento, algo que conduz à secularização que identifica o mundo exterior com estruturas racionais traduzíveis em linguagem matemática, à legitimação do poder pela eficiência, finalmente à ampliação do espaço em que age e pensa o indivíduo (FURTADO, 1984 in FURTADO, 2012, p. 35). Essa é uma alteração do processo cultural ocidental de amplitude significativa. A segunda frente desse processo deita raízes na expansão geopolítica viabilizada pelas navegações intercontinentais. O primeiro feixe partiu da Itália, o segundo de Portugal.

A cultura brasileira é um dos múltiplos frutos desse processo de mutação que assume a forma de desbordamento da cultura europeia a partir do início do século XVI. Mas tem de particular o haver emergido diretamente de um dos polos do duplo processo germinativo, o que deve ser tido em conta se pretendemos captar suas peculiaridades (FURTADO, 1984 in FURTADO, 2012, p. 35). Cabe lembrar que à frente do processo que culmina na "descoberta" do Brasil esteve o Estado português. Não menos importante é a relação que se estabeleceu entre este Estado e os grupos mercantis que capitanearam esse empreendimento; relação que se estendeu, posteriormente, à ocupação e exploração das terras brasileiras.

Conquanto tenha sido minoria ao longo de todo o período colonial, os portugueses exerceram papel fundamental na configuração da cultura brasileira. Não somente, e talvez nem principalmente, diz Furtado, porque eram senhores ante a maioria da população escrava ou quase escrava. Mas, sobretudo, porque "dispunham de técnicas mais avançadas e continuavam a alimentar-se de suas fontes culturais europeias, com as quais mantinham contato regular" (FURTADO, 1984 in FURTADO, 2012, p. 36-37). O envolvimento umbilical do Estado português com sua burguesia, em Portugal, e o domínio quase absoluto da Igreja e do Estado no período colonial brasileiro configuram o quadro histórico e institucional da formação cultural brasileira. É somente a partir da Revolução Industrial da Europa do século XVIII que se inicia o processo de rompimento da cultura brasileira com a herança barroca. O advento da Revolução Industrial representou uma transformação significativa na dinâmica econômica mundial da época. Ademais, ela exerceu influência sobre o desenvolvimento econômico ulterior de quase todas as regiões da Terra. Entretanto, o modo como estavam organizadas econômica e politicamente as sociedades antes do impacto com o tipo capitalista de produção que ganha preponderância a partir daí é o que definirá os traços da reconfiguração. 
Essencialmente inicia-se desse modo uma nova etapa do processo de modernização no Brasil, que significou, em resumo, "a utilização do excedente retido localmente para modelar os padrões de consumo de forma a facilitar o fluxo de importações e aprofundar a divisão internacional do trabalho" (FURTADO, 1984 in FURTADO, 2012, p. 38). Aí estão postos dois eixos articulatórios da teoria do subdesenvolvimento: (i) modernização dos padrões de consumo e (ii) configuração do sistema centro-periferia. O segundo lê-se numa chave fundamentalmente econômica, já que se funda na tese da deterioração dos termos de intercâmbio. $\mathrm{O}$ primeiro, que mais nos interessa neste momento, tem uma decorrência sociocultural relevante: ela significa a escolha social face ao excedente historicamente construído. Entre os interpretes que se debruçaram sobre a temática da cultura na obra de Furtado, Carlos Brandão é um dos que, aparentemente, mais conseguiu sintetizar o problema. Diz ele:

\begin{abstract}
O conceito de desenvolvimento proposto pela obra furtadiana se baseia no estudo da natureza do processo de exercitar opções alternativas frente a uma temporalidade construída mais larga (e não-imediatista), apta a escolhas autônomas, apresentando trajetórias abertas, sujeitas a decisões estratégicas, em ambiente de incerteza, e de diferenciação de poder (de comando sobre o destino) de agentes desigualmente constituídos. Parte de uma perspectiva que desenvolvimento, necessariamente envolve tempo e espaço nas decisões de como alocar (intertemporalmente, interespacialmente, intersetorialmente etc.) ativos, recursos, capacitações, produtivamente ou não, ou seja, envolve a questão da destinação do excedente social (BRANDÃO, 2012, p. 2-3).
\end{abstract}

Nos quadros da modernização dependente, no Brasil - mas também para a América Latina, se poderia arriscar a dizer -, o rompimento com o passado tradicional foi conduzido por uma síntese imitativa e não a um "novo processo cultural criativo, [...] [tal como] ocorrido na Europa com a passagem da visão do mundo medieval para o humanismo" (FURTADO, 2012, p. 38). O resultado desse processo será o distanciamento, no quadro das referências simbólicas, entre uma elite "hipnotizada" pelos bens culturais europeus e um povo que "segue seu curso próprio, reforçando sua autonomia criativa e diferenciando-se regionalmente" (FURTADO, 1984 in FURTADO, 2012, p. 39).

Num tipo de organização societal orientada para a acumulação a tendência é que os meios sejam vistos como fins, o que produz a ilusão, explica Furtado, de que o avanço da "racionalidade" signifique libertação, desalienação. Talvez esse seja o centro do raciocínio que conduz ao entendimento da distinção entre modernização e modernidade ${ }^{7}$. A primeira, como se disse anteriormente, é a representação da racionalidade instrumental e sua

\footnotetext{
${ }^{7}$ Para América Latina uma discussão sobre a distinção conceitual entre modernização e modernidade pode ser vista em: (BRAVO; MARTIN, 2010).
} 
penetrabilidade, a segunda é desígnio de um projeto político entre cujos valores fundantes estão o da liberdade e o da igualdade. Brandão sustenta, na mesma direção que Furtado, que há uma relação causal entre a reprodução do subdesenvolvimento e as formas de dependência cultural.

O elitismo nobilitador de posições da classe dominante, garantindo a recorrente assimilação, transplantação, modernização e ocidentalização dos estilos importados de vida, conduzirá ao deperecimento de sistemas de cultura. A difusão da civilização industrial, com a infiltração dos critérios de racionalidade instrumental irá enrijecer e disseminar a dependência cultural (BRANDÃO, 2012, p. 6).

Furtado está, desse modo, colocando no centro do debate a relação de interdependência que se estabelece entre o processo cultural, como construção de valores, significados e práticas, e o processo de modernização produtiva. A relação existente entre desenvolvimento e cultura é, certamente, bastante complexa. Aqui cumpre destacar que Furtado não comunga de uma visão essencialista da cultura, como se essa fosse uma dimensão autônoma e operasse como "polo positivo" do processamento histórico. Contrariamente, ele pareceu preocupar-se com a particularidade que a dimensão cultural assume no lado dependente da configuração centro-periferia.

\footnotetext{
Cabe, portanto, reconhecer que os povos do mundo periférico se confrontam com uma dupla crise: a da própria civilização industrial, decorrente do avanço progressivo da racionalidade instrumental, e a específica das economias periféricas, cuja situação de dependência cultural tende a agravar-se (FURTADO, 1974, p. 68).
}

Não há como afirmar, entretanto, qualquer forma de vínculo imanente entre a industrialização tardia e o tipo de forma social que predominará. Além do mais, há uma assertiva furtadiana insistentemente repetida em seus livros e artigos que parece atestá-la e nos reconduzir ao centro do problema que este artigo explora. Trata-se da ideia de que o processo de desenvolvimento só adquire concretude se "à aguda percepção do momento histórico, adiciona-se um elevado ingrediente de vontade coletiva" (FURTADO, 1984 in FURTADO, 2012, p. 31). E completa, é somente através da vontade coletiva que se pode orientar as forças criativas para a reformulação estrutural da sociedade "e a conquista de novos avanços na direção de formas superiores de vida" (FURTADO, 1984 in FURTADO, 2012, p. 31). A questão fundamental, então, diz respeito, às possibilidades e, de resto, aos entraves, que as formas como se relacionam a dimensões cultural, política e econômica conferem ao desenvolvimento.

\section{Considerações finais: os entrelaçamentos conceituais}


Em documentário cujas imagens foram gravadas pouco tempo antes de sua morte Celso Furtado dá mostras de que o acúmulo teórico e prático sobre o subdesenvolvimento brasileiro e latino americano lhe conduziu à resignação. Diz ele:

\begin{abstract}
Eu me dei conta desde muito cedo que havia países subdesenvolvidos que assim passaram etapas e etapas, cresceram muito sem nunca sair do subdesenvolvimento. [...] A dura verdade é que [...] os países que se integram no mercado internacional para através da divisão internacional do trabalho que nós conhecemos, e que, portanto, vão ficar subordinados ao comando de outras forças econômicas, esses não saem mais do subdesenvolvimento, estão condenados ao subdesenvolvimento $(\mathrm{O}$ LONGO..., 2004).
\end{abstract}

O que teria conduzido Furtado a pensar em termos de condenação ao subdesenvolvimento? A hipótese que lançamos aqui é a de que sua posição foi ganhando traços pessimistas à medida que seus estudos sobre o desenvolvimento foi-se preocupando com as questões extra econômicas. De mais a mais, uma das linhas possíveis para explicar sua gradativa atenção à dimensão cultural está, ao que parece, associada à ideia de que não há superação do subdesenvolvimento sem um radical processo de democratização do Estado e da sociedade. "No Brasil o debate sobre as opções do desenvolvimento demanda uma reflexão prévia sobre a nossa cultura, que ponha em relação a lógica dos fins, que a rege, e a dos meios, razão instrumental inerente à acumulação" (FURTADO, 1987 in FURTADO, 2012a, p. 186).

Nessa articulação, como aliás também aparece em grande parte de seus escritos, o Estado constitui-se como um agente relevante. Aí está um aspecto distintivo da obra de Furtado; toda sua elaboração teórica esteve resguardada por uma filosofia da práxis, como afirma Candido Mendes.

A reflexão de Celso teve a marca antológica do pensamento praxístico, nascido do aprofundamento, sem cortes, da meditação fundadora que retoma, revê, compara. Faz-se à flor do fenômeno global que se lhe desvela, e ao qual empresta, também, a sua própria intervenção (MENDES, 2005, p. 10).

Se bem que, gradativamente, sua aposta vai se deslocando dos centros de decisão para as sociedades civis, o Estado sempre foi pensado como agente indutor, quer na dinâmica econômica, quer na social e inclusive, vale dizer, na cultural. A concepção de política cultural pensada por Celso Furtado não diz respeito, exclusivamente, às ações para estímulo do consumo de bens culturais. "Em nossa época de intensa comercialização de todas as dimensões da vida social o objetivo central de uma política cultural deveria ser a liberação das 
forças criativas da sociedade" (FURTADO 1984 in FURTADO, 2012, p. 41). O que o autor quer dizer com isso?

Em dezenas de análises publicadas em livros e artigos Furtado bateu insistentemente na tecla da defasagem existente entre indicadores econômicos e sociais. Sobretudo após o setor industrial ter-se tornado centro dinâmico da economia nacional, algo que só ocorreu em meados do século XX, é inegável o aumento do ritmo de crescimento da economia. Assim como é inegável, diz ele, o alto custo social sob o qual se deu esse processo. "Ora, uma tendência estrutural de caráter antissocial requer, para ser modificada, uma deliberada ação política” (FURTADO, 1986 in FURTADO, 2012a, p. 62). Desse modo, segue ele:

os objetivos maiores da política de desenvolvimento têm que ser, entre nós, de
natureza social, ainda que os meios para alcança-los sejam com frequência de caráter
econômico. Ora, o que chamamos de política cultural não é senão um
desdobramento e um aprofundamento da política social (FURTADO, 1986 in
FURTADO, 2012a, p. 63).

No citado texto de 1974, como vimos, já está presente a ideia de que o desenvolvimento, em seu sentido mais profundo, diz respeito às opções criativas que as sociedades dão ao excedente que produzem. Institucionalmente, tais opções são concretizadas em forma de políticas sociais. Estas, por seu turno, são advindas dos conflitos operantes no interior do Estado e, eventualmente, dos espaços de interação entre Estado e sociedade. A história das sociedades ditas modernas já demonstrou que a "miséria absoluta somente foi abolida ali onde uma vontade política se propôs a esse objetivo" (FURTADO, 1986 in FURTADO, 2012a, p. 63-64). Isto é, as necessidades elementares da humanidade não foram resolvidas "naturalmente" pelas forças econômicas. O suposto filosófico adquire concretude na dialética do conflito Estado-sociedade.

A política cultural diz respeito, essencialmente, a essa ordem superior de
necessidades do homem. Em princípio, ela pressupõe, para ter credibilidade, uma
política econômica e social que assegure o emprego, o crescimento da economia e a
satisfação das necessidades básicas da população. Mas não tem fundamento
imaginar que somente as sociedades que já satisfazem suas necessidades de base
instintiva têm aspirações de ordens superiores (FURTADO, 1986 in FURTADO,
2012a, p. 64).

Com efeito, como afirma Carlos Brandão, desenvolvimento, no pensamento de Celso Furtado, é tensão; trata-se, diz ele, de "distorcer a correlação de forças, importunar diuturnamente as estruturas e coalizões tradicionais de dominação e reprodução do poder" (BRANDÃO, 2012, p. 4). Daí que a noção de desenvolvimento cultural é operacionalizada, por Furtado, como "a tomada de consciência do atraso acumulado na própria satisfação das 
necessidades básicas e da urgência de que sejam introduzidas mudanças estruturais na matriz do sistema econômico" (FURTADO, 1986 in FURTADO, 2012a, p. 64). Se observa aí que Furtado pensa o processo cultural integrado - dialeticamente - à questão distributiva. Deste ângulo parece axiomática a interdependência entre cultura, poder e desenvolvimento.

\footnotetext{
Por que o Brasil não reduziu o subdesenvolvimento, se o seu PIB cresceu 100 vezes no Século XX? Durante muitos anos trabalhei nesse tema, e só cheguei a perceber o âmago da questão quando introduzi o aspecto cultural. Alguns países podem ter crescimento econômico, a partir dos produtos primários. Terão aumento de renda, o qual poderá ser apropriado por uma minoria, por uma elite que adota, então, padrões de consumo e formas de viver típicas dos países mais ricos, e totalmente incompatíveis com o nível de renda do próprio país. Esse país crescerá economicamente, mas não se transformará, ao contrário, se deformará (FURTADO, 2003, p. 16).
}

A dimensão cultural ganha relevo, de fato, na medida em que a concepção de desenvolvimento deita raízes no processamento histórico de transformação do meio (natural, social, político, econômico) em dispositivo de acesso coletivo a formas superiores de vida, ou para usar um termo mais comum, de acesso a um maior bem-estar da coletividade. Os desdobramentos das reflexões de Celso Furtado a respeito do desenvolvimento e do subdesenvolvimento formam um conjunto de desafios que o pensamento social deve enfrentar. Seus esforços, repletos de intentos praxiológicos, são convites para a teorização sociológica. Afinal, reconhece o próprio autor, a teoria do subdesenvolvimento é tarefa uma ainda incompleta (O LONGO..., 2004).

\section{Referências}

AGARWALA, A.N.; SINGH, S.P (org.). A economia do subdesenvolvimento. Rio de Janeiro: Contraponto, 2010.

BIELSCHOWSKY, R. Sesenta años de la Cepal: estructuralismo y neoestructuralismo. Revista Cepal, Santiago, n. 97, p. 173-194, abril 2009

BRANDÃO, C. Celso Furtado: subdesenvolvimento, dependência, cultura e criatividade. Revista de Economia Política de las Tecnologias de la Información y de la Comunicación. São Cristovão/SE, Vol. XIV, ene-abr 2012.

BRAVO, Álvaro Marin; MARTIN, Juan Jesus Morales. Modernidad y modernización em América Latina: una aventura inacabada. Nómadas - Revista Crítica de Ciências Sociales e Jurídicas, n.26 v.2, 2010.

CEPÊDA, Vera Alves. O pensamento político de Celso Furtado: desenvolvimento e democracia. 
<http://www.centrocelsofurtado.org.br/adm/enviadas/doc/25_20060704234356.pdf. >. acesso em 22 de dezembro de 2014.

ELIAS, N. A sociedade dos indivíduos. Rio de Janeiro: Jorge Zahar, 1994.

ESTEVES, C. R. Desenvolvimento como cultura na obra de Celso Furtado. Cadernos do Desenvolvimento, Rio de Janeiro, v. 9, n. 14, p. 39-56, jan-jun 2014.

FURTADO, C. Que somos. In: FURTADO, R. F. D. Ensaio sobre cultura e o Ministério da Cultura. Rio de Janeiro: Contraponto, 2012. p. 29-42.

Pressupostos da política cultural. In: FURTADO, R. F. D. Ensaio sobre cultura e o Ministério da Cultura. Rio de Janeiro: Contraponto, 2012a. p. 61-66.

Letras, 2008.

Criatividade e dependência na civilização industrial. São Paulo: Companhia das Entrevista "O Brasil do Séc. XX" (concedida a Eduardo Pereira Nunes). Estatísticas do Século XX. Rio de Janeiro: IBGE, 2003.

Em Busca de um Novo Modelo: reflexões sobre a crise contemporânea. São Paulo, Paz e Terra: 2002.

Pequena introdução ao desenvolvimento: enfoque interdisciplinar. São Paulo: Nacional, 1980. 1978.

.Criatividade e dependência na civilização industrial. São Paulo: Círculo do livro,

O mito do desenvolvimento econômico. Rio de Janeiro: Paz e Terra, 1974.

A pré-revolução brasileira. Rio de Janeiro: Fundo de Cultura, 1962.

FURTADO, Rosa F. D. (org). Ensaios sobre cultura e o Ministério da Cultura. Rio de Janeiro: Contraponto; Centro Internacional Celso Furtado, 2012.

HIRSCHMAN, Albert. Ascensão e declínio da economia do desenvolvimento. Dados. Vol. 25, n. 1 , pp. $5-24,1982$.

HERMET, Guy. A democratização dos países emergentes e as relações entre o Estado, as OIGs e as ONGs. In: MILANI, C.; ARTURI, C; SOLINÍS, A. (org.). Democracia e governança mundial: que regulações para o século XXI? Porto Alegre: EdUFRGS/UNESCO, 2002.

KORNIS, George. A cultura no pensamento (e na ação) de Celso Furtado: desenvolvimento, criatividade, tradição e inovação. Novos estud. - CEBRAP, São Paulo , n. 96, July 2013 . Available from $\quad<$ http://www.scielo.br/scielo.php?script=sci_arttext\&pid=S0101- 
33002013000200012\&lng=en\&nrm=iso >. access on $05 \quad$ Jan. 2015. http://dx.doi.org/10.1590/S0101-33002013000200012.

MACHADO NETO, A. L. Sociologia do Desenvolvimento. Rio de Janeiro: Tempo Brasileiro, 1963

MENDES, C. Celso Furtado: Fundação e Prospectiva do Desenvolvimento. Dados, Rio de Janeiro, v. 48, n. 1, p. 7-20, 2005.

MEIER, Gerald; SEERS, Dudley (org.). Pioneros del desarrollo. Madrid: Tecnos, 1986.

O LONGO amanhecer. Direção de José Mariani, Rio de Janeiro, Videofilmes, 2004. 1 DVD. PEREIRA, L. Ensaios de Sociologia do Desenvolvimento. São Paulo: Pioneira, 1970.

PINTO, L. A. C. Sociologia e Desenvolvimento. Rio de Janeiro: Civilização Brasileira, 1965.

RODRIGUEZ, O. Furtado e a renovação da agenda do desenvolvimento. In: SABOIA, J. E. C. F. J. C. Celso Furtado e o século XXI. Barueri; Rio de Janeiro: Manole; IE-UFRJ, 2007. Cap. 1, p. 445.

SACHS, W. Diccionário del Desarrollo: una guia de conocimiento como poder. Lima: Pratec, 1996.

VEIGA, José Eli da. Desenvolvimento sustentável: o desafio do século XXI. Rio de Janeiro: Garamond, 2010.

Recebido em agosto de 2018

Aprovado em dezembro de 2018 